\title{
High pressure solubility data of carbon dioxide in (tri-iso-butyl(methyl)phosphonium tosylate + water) systems
}

\author{
Sónia P.M. Ventura ${ }^{\text {a }}$, Jérôme Pauly ${ }^{\text {b }}$, Jean L. Daridon ${ }^{b}$, J.A. Lopes da Silva ${ }^{\text {a }}$, Isabel M. Marrucho ${ }^{\text {, }}$, \\ Ana. M.A. Dias ${ }^{c}$, João A.P. Coutinho ${ }^{\text {a,* }}$ \\ ${ }^{a}$ CICECO, Departamento de Química, Universidade de Aveiro, 3810-193 Aveiro, Portugal \\ ${ }^{\mathrm{b}}$ Laboratoire Haute Pression Centre Universitaire de Recherche Scientifique, Université de Pau, Avenue de l'Université, 64000 Pau, France \\ ${ }^{\mathrm{C}}$ IBB-Instituto de Biotecnologia e Bioengenharia, Centro de Engenharia Biológica, Universidade do Minho, Campus de Gualtar, 4710-553 Braga, Portugal
}

\section{A R T I C L E I N F O}

Article history:

Received 3 October 2007

Received in revised form 8 April 2008

Accepted 16 April 2008

Available online 24 April 2008

\section{Keywords:}

Gas solubility

High pressure

Ternary system

Carbon dioxide

Phosphonium

Water

\begin{abstract}
A B S T R A C T
Ionic liquids are attracting great attention nowadays due to their interesting properties which make them useful in a broad range of applications including reaction media or separation/capture of environmentally hazardous gases such as carbon dioxide. In many cases, for practical and/or economical reasons, the use of aqueous solutions of ILs would be preferable to their use as pure compounds.

In this work, high pressure equilibrium data for the carbon dioxide $\left(\mathrm{CO}_{2}\right)+$ tri-iso-butyl(methyl)phosphonium tosylate $\left[i \mathrm{Bu}_{3} \mathrm{MeP}\right][\mathrm{TOS}]+$ water system were measured at temperatures ranging from (276 to 370$) \mathrm{K}$ and pressures up to $100 \mathrm{MPa}$. Measurements were performed using a high-pressure cell with a sapphire window that allows direct observation of the liquid-vapour transition. Mixtures with different IL concentrations were studied in order to check the influence of the amount of IL on the solubility of $\mathrm{CO}_{2}$ in the aqueous mixture.

The results show that the presence of IL enhances the solubility of $\mathrm{CO}_{2}$ in the (IL + water) system revealing a salting-in effect of the IL on the solubility of $\mathrm{CO}_{2}$. The appearance of a three phase region was observed for IL concentrations higher than $4 \mathrm{~mol} \%$ of IL in water when working at pressures between 4 and $8 \mathrm{MPa}$ and temperatures between (280 and 305) K. In this range, the upper limit of the VLE region observed is shown to increase with the temperature being almost independent of the IL initial concentration in the mixture.
\end{abstract}

(c) 2008 Elsevier Ltd. All rights reserved.

\section{Introduction}

Ionic liquids (ILs) are a novel class of solvents which are being the focus of much research in recent years due to the interesting conjugation of properties that characterize them [1,2].

ILs are generally composed by a large asymmetric organic cation and either an organic or inorganic anion. A key feature of these compounds is that their physical properties can be tailored by the judicious selection of the cation and/or the anion [3-5]. The asymmetry of the cation is believed to be responsible for the low melting temperatures $\left(<100^{\circ} \mathrm{C}\right)$ of ILs, while the nature of the anion is considered to be responsible for many of the physical properties of these compounds such as their miscibility with conventional solvents, density, viscosity, Lewis acidity, hydrophobicity, hydrogen-bonding capability and hygroscopicity [6]. Moreover their insignificant vapour pressures, reduces environmental pollution and highly reduces working exposure hazards in comparison with

\footnotetext{
* Corresponding author. Tel.: +351 234401 507; fax: +351234370 084.

E-mail address: jcoutinho@ua.pt (J.A.P. Coutinho).
}

the conventional organic solvents currently being used in the industry [7]. These, allied with their thermal and chemical stability and good solvency power for both organic and inorganic materials, polar and non-polar compounds [8,9], turn these compounds in valuable substitutes for traditional solvents.

The higher solubility of gases in ILs when compared to common solvents aroused the interest of the scientific community, as recent literature on the subject reports [5,7,10-16]. One of the most interesting and valuable application of this property is the possibility of using ILs as $\mathrm{CO}_{2}$ removal agents from gaseous effluents. This process is usually done through aqueous solutions of primary alkanolamines $[17,18]$ which have been traditionally used in the natural gas processing industry for the sweetening process removal of acid gases according to the following equation:

$$
\mathrm{C}_{n} \mathrm{H}_{2 n} \mathrm{OHNH}_{2}+\mathrm{CO}_{2}+\mathrm{H}_{2} \mathrm{O} \rightarrow \mathrm{C}_{n} \mathrm{H}_{2 n} \mathrm{OHNH}_{3}^{+}+\mathrm{HCO}_{3}^{-}
$$

However, there are several drawbacks associated with the use of primary alkanolamines due to their volatility. In this regard and having in mind the actual concerning to largely reduce the $\mathrm{CO}_{2}$ atmospheric emissions, it is crucial to look for a new kind of 
removal agent(s) preferably characterized by negligible vapour pressure and high stability [19]. ILs have been presented as interesting valuable alternatives to traditional removal agents $[19,20]$.

Research regarding the solubility of gases in ILs have been so far most centred on the study of the solubility of gases in imidazolium based ILs. Gases such as light alkanes and alkenes, oxygen, nitrogen, hydrogen, argon, carbon monoxide and $\mathrm{CO}_{2}$ are among the most studied. Particular attention is being given to $\mathrm{CO}_{2}$ due to the interesting behaviour observed when this gas is used as supercritical fluid [21-24]. The successful application of supercritical $\mathrm{CO}_{2}$ for separation and purification of products from ILs, by using the gas as a co-solvent in extractions or as an anti-solvent in precipitations, is the main reason of the attention given to this gas $[21,23-26]$. The procedure avoids the problems related with traditional separation techniques such as the loss of solvent, cross-contamination, and destruction of thermo-sensible compounds, and allows reactants and products to be extracted from ILs with subsequent recycle and reuse of the IL [26].

Another very interesting aspect is that, the use of $\mathrm{CO}_{2}$ can induce the formation of an additional liquid phase that is rich in IL, even when the original solution is quite dilute in IL. Moreover, besides promoting the separation of IL/organic phases, the technique proved to be able to promote the separation of both hydrophobic and hydrophilic imidazolium based ILs from aqueous solutions $[27,28]$ with relatively low-pressure gaseous $\mathrm{CO}_{2}$. For certain $(p, T, x)$ conditions, ternary $\left(\mathrm{CO}_{2}+\mathrm{IL}+\right.$ organic or water $)$ systems present a phase split with the appearance of a (vapour + liquid + liquid) equilibrium (VLLE) characterized by one liquid phase richer in IL, a second liquid phase richer in organic or water and a third gaseous phase rich in $\mathrm{CO}_{2}$. This behaviour was previously reported in the literature by Aki et al. [11] and Zhang et al. [16,29] for $\left(\mathrm{CO}_{2}+\right.$ imidazolium IL + organic) and by Scurto et al. [11] and Zhang et al. [28] for $\left(\mathrm{CO}_{2}+\right.$ imidazolium IL + water $)$ ternary systems. The interesting aspect to point out is that the VLLE is observed at relatively mild thermodynamic conditions. At those conditions, a slight increase in pressure enriches each of the phases in a preferential component, promoting the separation of the ternary mixture at economic and safe conditions.

As mentioned above, there are few works concerning the solubility of gases in phosphonium based ILs. The studied gases include $\mathrm{CO}_{2}[15,30,31]$ and light alkanes and alkenes [30,31]. Anthony et al. [32] studied the solubility of oxygen and $\mathrm{CO}_{2}$ in $\left[i \mathrm{Bu}_{3} \mathrm{MeP}\right][\mathrm{TOS}]$ but only at $323.15 \mathrm{~K}$. Hutchings et al. [33] observed that the solubility of one phosphonium based IL in dense $\mathrm{CO}_{2}$ is surprisingly high in contrast to the solubility behaviour of imidazolium-based ILs. Ion pair formation in the gaseous phase was pointed as the main reason for this behaviour. The ion-paired IL can be viewed as one molecular unit bearing a dipole moment that interacts with the quadrupole moment of $\mathrm{CO}_{2}$. Recently, Ferguson and Scovazzo [30] have shown that imidazolium and phosphonium based ILs have similar solubilities for several gases. Being about 10 times cheaper, phosphonium based ILs can represent a low-cost alternative to imidazolium ILs, however, their higher viscosities difficult the diffusion of gases through the liquid. A possible way to overcome this problem consists in the use of an aqueous solution of the IL instead of the pure compound. Besides reducing the total amount of IL required this would also diminish the IL viscosity.

Despite the mechanistic and practical implications that ternary $\mathrm{CO}_{2} / \mathrm{IL} /$ water solubility data may represent for both reaction and separation systems, the fact is that literature data regarding these systems is still scarce. Considering the potential alternative that phosphonium ILs represent, the solubility of $\mathrm{CO}_{2}$ in aqueous solutions of $\left[i \mathrm{Bu}_{3} \mathrm{MeP}\right][\mathrm{TOS}]$ with different IL concentrations, was studied in this work.

Previous studies $[28,34]$ have reported the influence of the presence of water on the solubility of gases in ILs showing that the sol- ubility decreases with the increase of the water content in the solution, which can be explained by the lower solubility of the gases in water when compared to their solubilities in the IL. In this work, the focus goes to the study of the solubility of $\mathrm{CO}_{2}$ in (IL + water) in which water is the main component in molar terms. It is important to notice that the mixtures studied composed by (3, 8 , and 12 ) $\mathrm{mol} \%$ of IL in water actually contain $47.35 \%, 65.24 \%$, and $74.64 \%$ in terms of IL mass fractions. By the addition of water, the viscosity of the system decreases to 'workable' values broadening the application possibilities of the IL. The aim of this study is to see how the reduction in the viscosity of the aqueous solutions of IL will affect its capacity to solubilize gases as $\mathrm{CO}_{2}$. In addition, a range of $(p, x, T)$ conditions necessary to induce the two liquid phases separation is presented and compared whenever possible to the ones previously reported for the $\mathrm{CO}_{2}+$ water + imidazolium based IL $[27,28,34]$.

\section{Experimental section}

The $\mathrm{CO}_{2}$ used was obtained from Messer with a purity of $99.995 \%$ and the $\left[i \mathrm{Bu}_{3} \mathrm{MeP}\right][\mathrm{TOS}]$ from Cytec with a purity of $98 \%$ checked by n.m.r. The IL was dried under vacuum at $80^{\circ} \mathrm{C}$ for $24 \mathrm{~h}$ before the measurements. Its final aspect was a very pale yellow colour. The IL's water content was measured with a Metrohm 831 Karl Fischer (KF) coulometer and was about 3585 ppm in mass fraction. This water content was taken into account in the preparation of the mixtures with water.

The apparatus and the measurement procedure followed have been previously described in detail [35-37]. The variable volume high pressure cell sketched in figure 1 consists in a horizontal hollow stainless steel cylinder closed at one end by a movable piston and one sapphire window at the other end allowing for visual observation of the fluid. A video acquisition system, made up of an endoscope plus a video camera, is placed behind the sapphire windows and displays on a computer screen the behaviour of the fluid inside the measuring cell.

The temperature is kept constant by circulating a heat-carrier fluid through three flow lines directly managed in the cell. This heat-carrier fluid is thermo-regulated with temperature stability of $0.01 \mathrm{~K}$ by means of a thermostat bath circulator (Huber Ministat CC1). The temperature is measured with a high precision thermometer, Model PN 5207 with an accuracy of $0.01 \mathrm{~K}$ connected to a calibrated platinum resistance inserted inside the cell close to the sample. The pressure is measured by a piezoresistive silicon

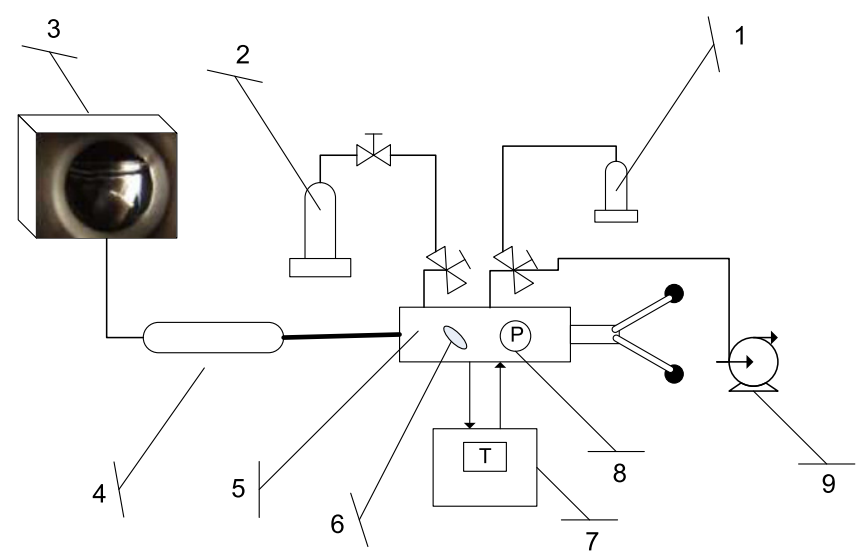

FIGURE 1. Schematic apparatus: 1 , aqueous solutions of IL; $2, \mathrm{CO}_{2} ; 3$, screen; 4 , endoscope plus a video camera; 5 , high-pressure variable-volume cell; 6 , magnetic bar; 7 , thermostat bath circulator; 8 , piezoresistive pressure transducers; 9 , vacuum pump. 
pressure transducer (Kulite) fixed directly inside the cell to reduce dead volumes previously calibrated using a dead weight gauge (Bundenberg) with accuracy better than $0.02 \%$. The accuracy of the transducer in the experimental range studied is $0.2 \mathrm{MPa}$.

The aqueous solutions of IL, previously prepared by weighting the exact amounts of dried IL and ultra pure water, are introduced in the high pressure cell by vacuum extraction. The exact mass introduced is determined by weighting the liquid container with a precision balance (Ohaus) with an accuracy of $0.1 \mathrm{mg}$. $\mathrm{CO}_{2}$ is then introduced under pressure from an aluminium reservoir tank (Gerzat) fixed in the plate of high weight/high precision balance with an accuracy of $1 \mathrm{mg}$ (Sartorius) and connected to the measuring cell by means of a flexible high pressure capillary. Once the ternary

TABLE 1

Viscosity data $(\eta)$ at $20^{\circ} \mathrm{C}$ for $\left(\left[i \mathrm{Bu}_{3} \mathrm{MeP}\right][\mathrm{TOS}]+\right.$ water $)$ at different IL concentrations and respective standard deviations $(\sigma)$

\begin{tabular}{ll}
\hline Mass fraction $\mathrm{IL} \pm 0.0001 /(\mathrm{w} / \mathrm{w})$ & $\left(\eta \pm \sigma^{\mathrm{a}}\right) \times 10^{3} /(\mathrm{Pa} \cdot \mathrm{s})$ \\
\hline 0.0000 & $0.89[40]$ \\
0.1250 & $1.65 \pm 0.08$ \\
0.2500 & $2.6 \pm 0.1$ \\
0.3750 & $4.0 \pm 0.2$ \\
0.5000 & $6.9 \pm 0.3$ \\
0.6250 & $11.6 \pm 0.5$ \\
0.7500 & $23.0 \pm 0.7$ \\
0.8720 & $68 \pm 2$ \\
1.0000 & $1320 \pm 13$ \\
\hline
\end{tabular}

mixture of known composition reaches the desired temperature, the pressure is slowly increased until the system becomes homogeneous. The pressure at which the last bubble disappears represents the equilibrium pressure for that temperature. For each temperature the measurement is repeated three times. During the experiment, the mixture is continuously stirred at high frequency to keep the system in equilibrium during the compression. When measuring the VLLE data, the temperature is kept constant and the pressure is raised until the presence of two different liquid phases is observed. Then, the pressure is decreased until the appearance of the gaseous phase.

The viscosity of the ionic liquid was measured using a controlled stress rheometer (Bohlin CVO $120 \mathrm{HR}$ ) equipped with cone-and-plate geometry (angle $4^{\circ}$, diameter $4 \mathrm{~cm}$ ). Steady shear tests at $20.0^{\circ} \mathrm{C}$ were performed by applying a shear stress ramp, between ( 0.01 and 10) Pa. The flow curves obtained confirmed the expected Newtonian behaviour for the IL aqueous solutions, within the shear range analyzed. Newtonian viscosity values were then calculated for each IL $\left\{\left(\left[i \mathrm{Bu}_{3} \mathrm{MeP}\right][\mathrm{TOS}]\right)+\right.$ water $\}$ at constant shear stress/shear rate ratio.

\section{Results and discussion}

The viscosities of aqueous solutions of $\left[i \mathrm{Bu}_{3} \mathrm{MeP}\right][\mathrm{TOS}]$ are reported in table 1 . A very strong variation of the viscosity with water concentration is observed in particular for solutions very rich in IL, with variations of one order of magnitude in the viscosity for changes of less than $0.1 \mathrm{w} / \mathrm{w}$ of water content. The mixtures

TABLE 2

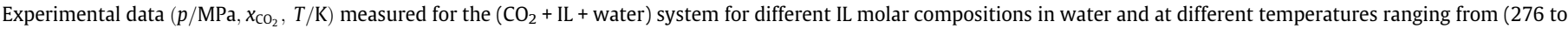
370) K

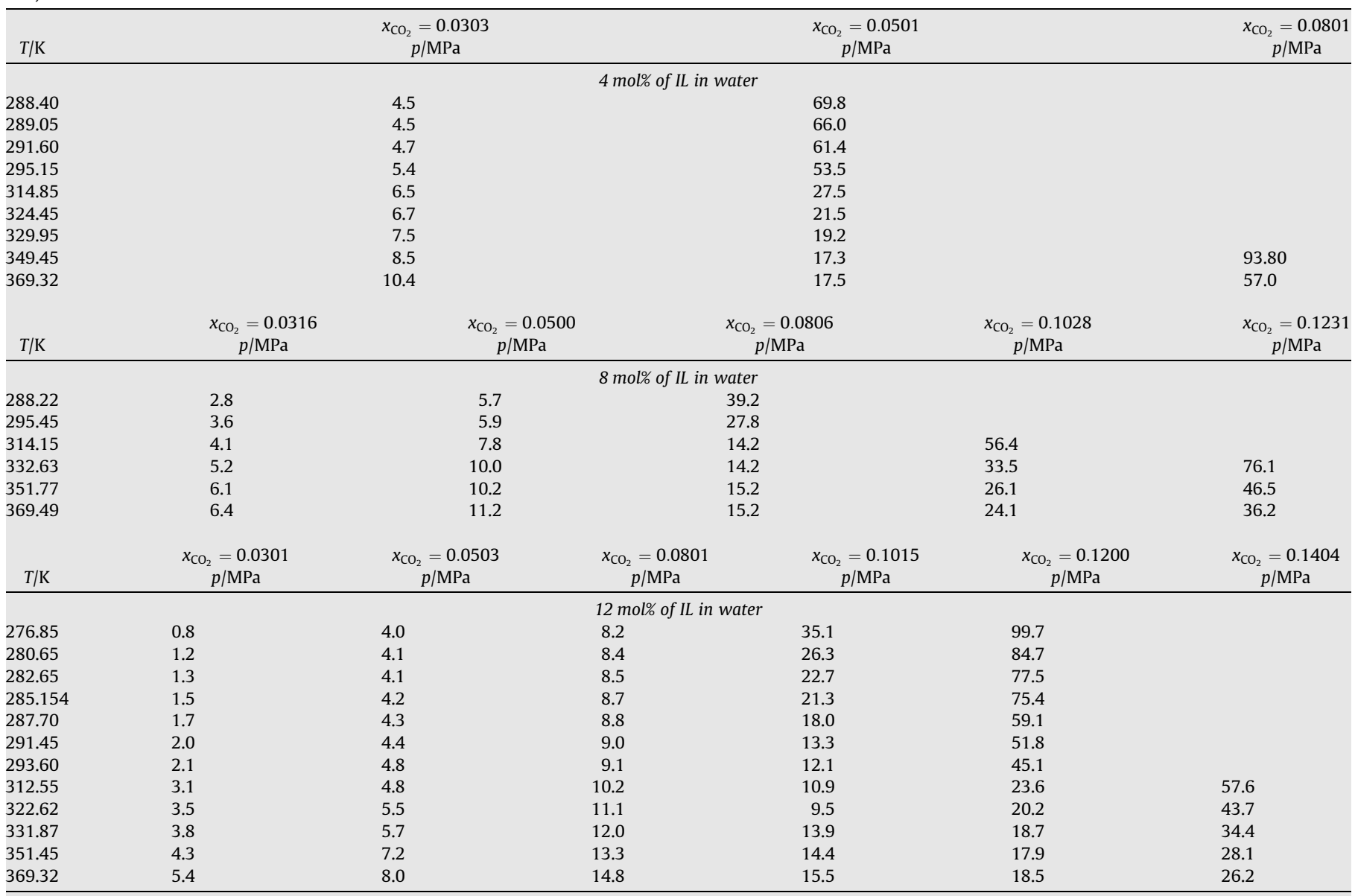


studied present low viscosities being easily manipulated with conventional pumps.

The solubility of $\mathrm{CO}_{2}$ in solutions of $(4,8$, and 12$) \mathrm{mol} \%$ of $\left[i \mathrm{Bu}_{3} \mathrm{MeP}\right][\mathrm{TOS}]$ in water was measured at pressures up to $100 \mathrm{MPa}$ and temperatures from (275 to 370 ) $\mathrm{K}$ as reported in table 2. Table 3 presents the thermodynamic conditions at which a VLLE line marks the phase boundary between the LLE and VLE regions.

The pressure/temperature experimental data for the solution of $8 \mathrm{~mol} \%$ of IL in water is depicted in figure 2. Considering a fixed molar composition of gas and temperature, the higher the pressure required to solubilize all the gas, the lower its solubility. Having this in mind, in figure 2 it can be observed that for $x_{\mathrm{CO}_{2}}=0.0316$, $x_{\mathrm{CO}_{2}}=0.0500$, and $x_{\mathrm{CO}_{2}}=0.0806$ above $310 \mathrm{~K}$ the solubility of $\mathrm{CO}_{2}$ presents a regular behaviour with temperature, with the gas solubility decreasing when temperature increases. When attempting to solubilize higher amounts of $\mathrm{CO}_{2}$, a liquid-liquid region appears as pressure increases and temperature decreases.

The pressure-composition projection of that same system is presented in figure 3 for various temperatures. It is clear from the figure that it is possible to solubilize up to $x_{\mathrm{CO}_{2}}=0.10$ in (IL + water) with pressures lower than $20 \mathrm{MPa}$. However, the equilibrium pressure increases very sharply for increasing concentrations of $\mathrm{CO}_{2}$ with the appearance of a two-phase region extending up to very high pressures. A similar behaviour was observed by Shariati and Peters $[7,38,39]$ when studying binary systems of $\mathrm{CO}_{2}$ plus imidazolium based ILs. As mentioned by the authors, this is a very unusual behaviour when comparing with the traditional closed phase envelope usually observed for the solubility of $\mathrm{CO}_{2}$ at high pressures.

As mentioned before, ternary $\left(\mathrm{CO}_{2}+\mathrm{IL}+\right.$ organic or water $)$ systems are characterized by the appearance of a liquid-liquid phase split over certain $(p, T, x)$ conditions with the appearance of a second liquid phase along with the gaseous $\mathrm{CO}_{2}$ rich phase. In this

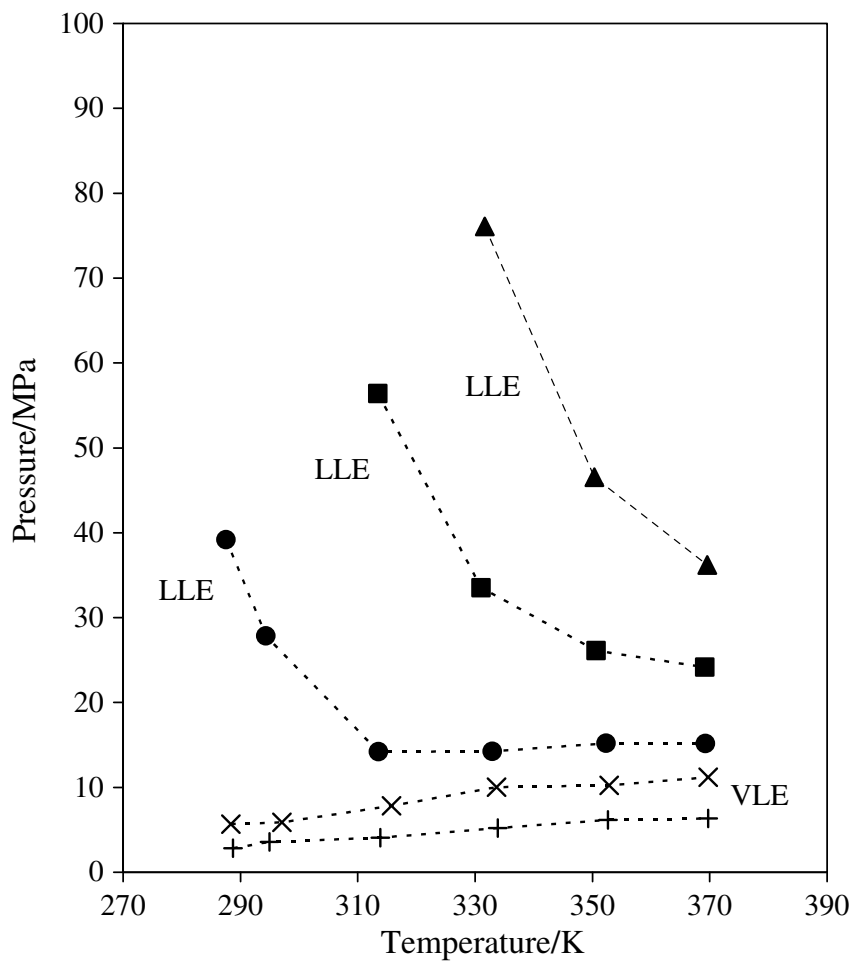

FIGURE 2. Pressure-temperature diagram for the solubility of $\mathrm{CO}_{2}$ in a solution of $8 \mathrm{~mol} \%$ of IL in water for various gas contents: $x_{\mathrm{CO}_{2}}=0.0316(+), x_{\mathrm{CO}_{2}}=0.0500(\times)$, $x_{\mathrm{CO}_{2}}=0.0806(\bullet), x_{\mathrm{CO}_{2}}=0.1028(\boldsymbol{\square})$, and $x_{\mathrm{CO}_{2}}=0.1231(\boldsymbol{\Delta})$. Lines are only a guide for the eye. work this behaviour was also observed and figure 4 represents on a $p-T$ diagram the upper limit of the VLE region observed. The VLE line for pure $\mathrm{CO}_{2}[40]$ as well as the results previously reported in the literature for analogous systems $[11,28]$ are also represented in this figure. There are a number of curious features related to this line marking the upper limit of the VLE region. In all cases it increases with the temperature and for the IL composition range

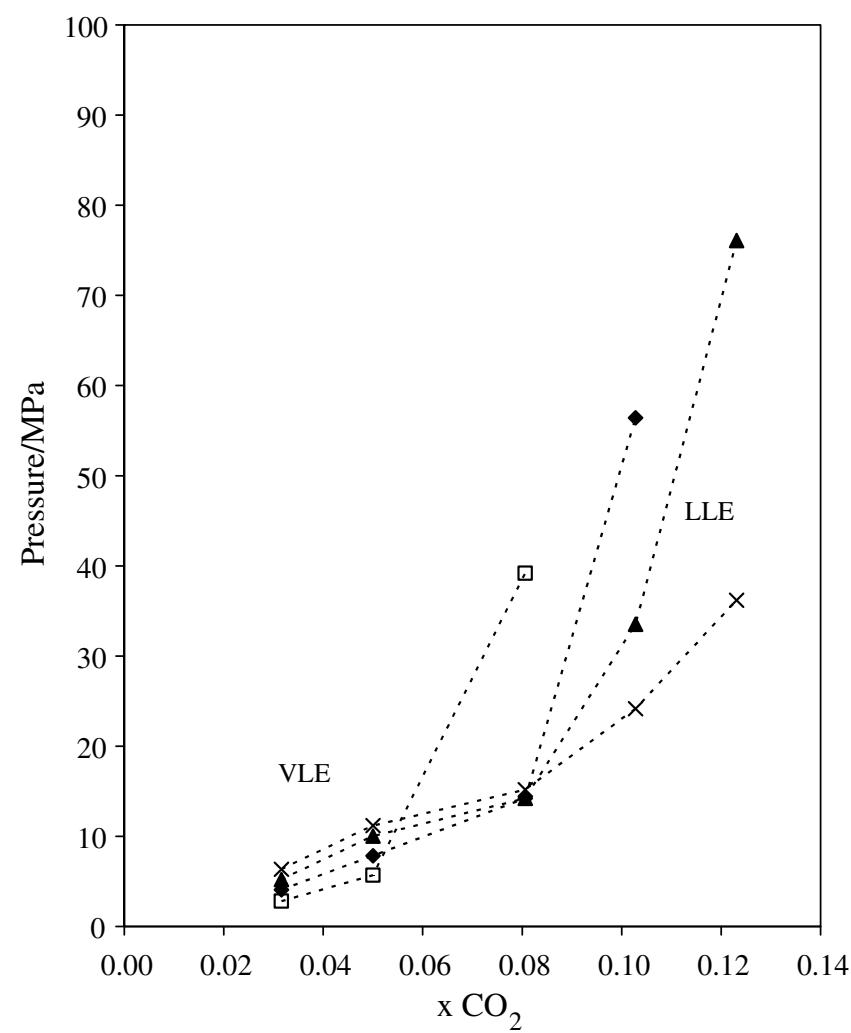

FIGURE 3. Experimental and interpolated solubility data for $\mathrm{CO}_{2}$ in a solution of $8 \mathrm{~mol} \%$ of IL in water at different temperatures: $288.22 \mathrm{~K}(\square), 314.15 \mathrm{~K}(\bullet), 332.63 \mathrm{~K}$ $(\Delta)$ and $369.49 \mathrm{~K}(\times)$. Lines are only a guide for the eye.

TABLE 3

Dependence of the VLLE line on the initial IL concentration and temperature for the ternary $\left(\left[i \mathrm{Bu}_{3} \mathrm{MeP}\right][\mathrm{TOS}]+\right.$ water $\left.+\mathrm{CO}_{2}\right)$ system

\begin{tabular}{|c|c|c|c|c|c|c|c|}
\hline \multicolumn{8}{|c|}{$4 \mathrm{~mol} \%$ of IL in water and $x_{\mathrm{CO}_{2}}=0.0501$} \\
\hline$T / \mathrm{K}$ & 278.85 & 284.05 & 288.05 & 293.25 & 298.15 & 306.15 & 307.35 \\
\hline p/MPa & 3.9 & 4.5 & 4.9 & 5.3 & 6.1 & 6.5 & 6.8 \\
\hline \multicolumn{8}{|c|}{$4 \mathrm{~mol} \%$ of IL in water and $x_{\mathrm{CO}_{2}}=0.0801$} \\
\hline$T / \mathrm{K}$ & 278.75 & 279.25 & 284.15 & 288.25 & 293.65 & 297.15 & 305.65 \\
\hline p/MPa & 3.9 & 3.9 & 4.5 & 5.0 & 5.6 & 6.2 & 7.5 \\
\hline \multicolumn{8}{|c|}{$8 \mathrm{~mol} \%$ of IL in water and $x_{\mathrm{CO}_{2}}=0.0806$} \\
\hline$T / \mathrm{K}$ & 280.65 & 281.65 & 286.35 & 290.25 & 295.25 & & \\
\hline$p / \mathrm{MPa}$ & 4.1 & 4.3 & 4.7 & 5.0 & 5.2 & & \\
\hline \multicolumn{8}{|c|}{$8 \mathrm{~mol} \%$ of IL in water and $x_{\mathrm{CO}_{2}}=0.1028$} \\
\hline$T / \mathrm{K}$ & 278.65 & 283.45 & 288.95 & 294.95 & & & \\
\hline p/MPa & 4.0 & 4.5 & 5.2 & 5.9 & & & \\
\hline \multicolumn{8}{|c|}{$8 \mathrm{~mol} \%$ of IL in water and $x_{\mathrm{CO}_{2}}=0.1231$} \\
\hline$T / \mathrm{K}$ & 279.15 & 284.45 & 293.35 & 298.25 & 303.55 & & \\
\hline$p / \mathrm{MPa}$ & 4.0 & 4.56 & 5.7 & 6.5 & 7.2 & & \\
\hline \multicolumn{8}{|c|}{$12 \mathrm{~mol} \%$ of IL in water and $x_{\mathrm{CO}_{2}}=0.1200$} \\
\hline$T / \mathrm{K}$ & 282.35 & 283.65 & 286.15 & 287.85 & 290.75 & 293.65 & 298.35 \\
\hline p/MPa & 4.5 & 4.5 & 5.2 & 5.2 & 5.5 & 6.0 & 6.6 \\
\hline \multicolumn{8}{|c|}{$12 \mathrm{~mol} \%$ of IL in water and $x_{\mathrm{CO}_{2}}=0.1404$} \\
\hline$T / \mathrm{K}$ & 279.45 & 285.05 & 288.95 & 293.45 & 297.45 & 302.35 & \\
\hline$p / \mathrm{MPa}$ & 4.1 & 5.1 & 5.3 & 5.9 & 6.4 & 7.2 & \\
\hline
\end{tabular}




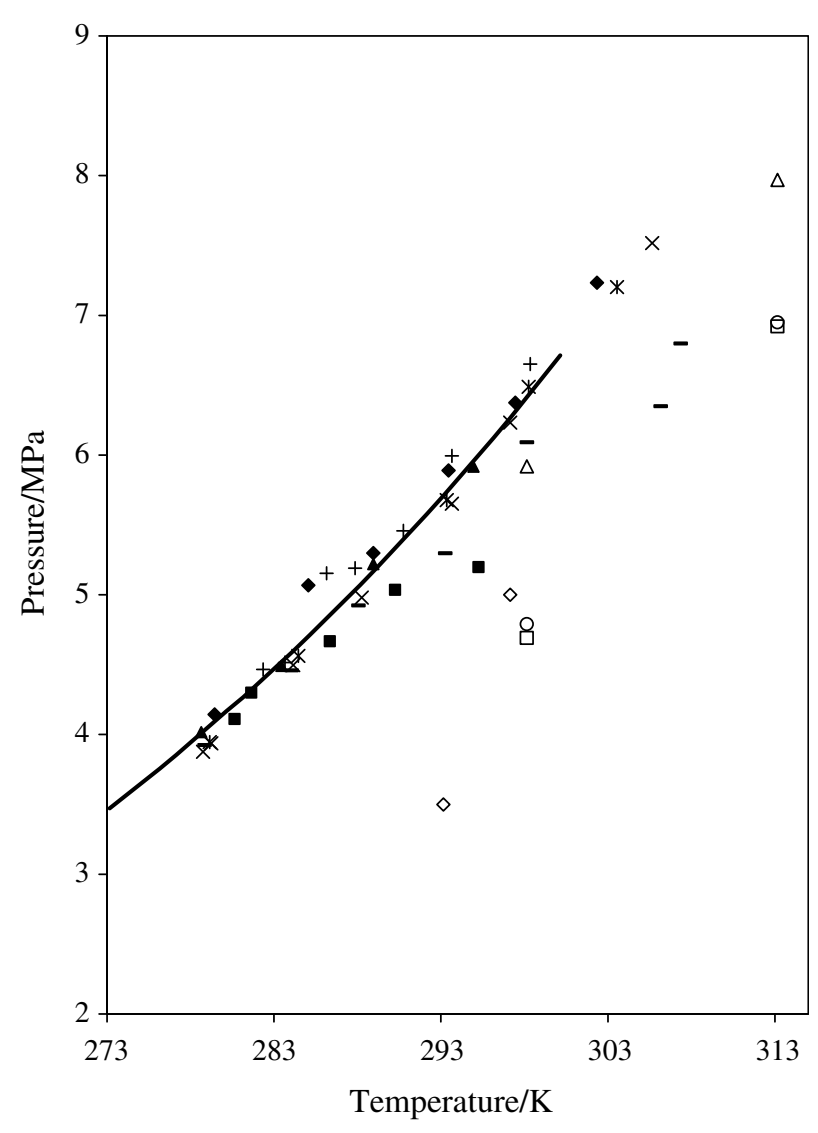

FIGURE 4. Diagram for the upper limit of the three phase zone for all the systems studied in this work: $x_{\mathrm{CO}_{2}}=0.05$ and $4 \mathrm{~mol} \%$ of IL in water $(-), x_{\mathrm{CO}_{2}}=0.08$ and $4 \mathrm{~mol} \%$ of IL in water $(\times), x_{\mathrm{CO}_{2}}=0.08$ and $8 \mathrm{~mol} \%$ of IL in water $(\boldsymbol{\square}), x_{\mathrm{CO}_{2}}=0.10$ and $8 \mathrm{~mol} \%$ of IL in water $(\boldsymbol{\Delta}), x_{\mathrm{CO}_{2}}=0.12$ and $8 \mathrm{~mol} \%$ of IL in water $(*), x_{\mathrm{CO}_{2}}=0.12$ and $12 \mathrm{~mol} \%$ of IL in water (+), and $x_{\mathrm{CO}_{2}}=0.14$ and $12 \mathrm{~mol} \%$ of IL in water ( ) and data reported in the literature: $0.1 \mathrm{~mol} \%(\triangle), 4.9 \mathrm{~mol} \%(\bigcirc)$, and $9.0 \mathrm{~mol} \%(\square)$ of [bmim] $\left[\mathrm{PF}_{6}\right]$ in water plus $\mathrm{CO}_{2}$ until phase separation is observed [11]; $7.7 \mathrm{~mol} \%$ of $[\mathrm{bmim}]\left[\mathrm{PF}_{6}\right]$ in water and $2.3 \mathrm{~mol} \%$ of $\mathrm{CO}_{2}$ in the IL rich phase [28] $(\diamond)$ and pure $\mathrm{CO}_{2}$ [40] (line).

studied in this work, it is essentially independent of the initial IL concentration in the aqueous solution. This line is also, within the experimental uncertainty, coincident with the VLE line for pure $\mathrm{CO}_{2}[40]$ and the appearance of the three phase region only occurs while the working conditions are below the critical point of pure $\mathrm{CO}_{2}$.

These observations are not novel as Aki et al. [11] observed the same behaviour for mixtures with concentration of IL in water higher than $5 \mathrm{~mol} \%$ but they give a clear indication that the second liquid phase results from the condensation of the $\mathrm{CO}_{2}$ as it crosses, with increasing pressure, the dew point line that, for mixtures with less volatile compounds, will occur at pressures somewhat below those of pure $\mathrm{CO}_{2}$. The boiling temperature line for the $\mathrm{CO}_{2}$ rich phase will occur for higher pressures, close to those of pure $\mathrm{CO}_{2}$, due to the very high concentration of gas in this phase. The mixture will thus behave almost as pure $\mathrm{CO}_{2}$ showing a bubble point very close to the saturation line of $\mathrm{CO}_{2}$. The high $\mathrm{CO}_{2}$ content of the second liquid phase is also reported by other authors [16].

\section{Conclusions}

New high pressure equilibrium data for $\left(\mathrm{CO}_{2}+\left[i \mathrm{Bu}_{3} \mathrm{MeP}\right]\right.$ [TOS] + water) systems were measured at temperatures ranging from (276 to 370 ) $\mathrm{K}$ and pressures up to $100 \mathrm{MPa}$. VLLE data were also observed and the thermodynamic conditions at which the second liquid phase appears were reported.
The measured data show that the temperature dependence of the $\mathrm{CO}_{2}$ solubility presents a regular behaviour with the gas solubility decreasing with an increase in the temperature when the gas composition is below $x_{\mathrm{CO}_{2}}=0.10$. For higher $\mathrm{CO}_{2}$ concentrations, a LLE was observed depending on the $P-T$ working conditions. The results also show that the solubility of carbon dioxide in the aqueous $\left[i \mathrm{Bu}_{3} \mathrm{MeP}\right][\mathrm{TOS}]$ system increase with the increase of IL molar composition revealing a salting-in effect promoted by the IL. It is shown that although the solubility of $\mathrm{CO}_{2}$ in the aqueous mixture is, as expected, lower than in the pure IL, it is still possible to solubilize significant amounts of gas in aqueous solutions of ILs with the advantage much lower viscosities of the aqueous mixtures, hopefully promoting gas diffusion and reducing operational constrains on the use of these fluids.

The formation of two liquid phases, one rich in $\mathrm{CO}_{2}$ and the other rich in water, which was observed at mild thermodynamic conditions can represent an interesting alternative for separation processes involving systems similar to the ones reported in this work. Moreover, it was observed that the VLLE line was almost independent of the IL initial composition in the solution and that it coincides with the VLE data for pure $\mathrm{CO}_{2}$ a clear indication that the condensed phases are mainly constituted by condensed $\mathrm{CO}_{2}$.

\section{Acknowledgements}

This work was supported by FEDER and Fundação para a Ciência e a Tecnologia (Project POCI/EQU/58152/2004). S.P.M. Ventura thanks CICECO, University of Aveiro, for a young researcher grant. The authors acknowledge the help of P.J. Carvalho on the viscosity measurements.

\section{References}

[1] P. Wasserscheid, W. Keim, Angew. Chem., Int. Ed. 39 (21) (2000) 3773-3789.

[2] R.D. Rogers, K.R. Seddon, Science 302 (5646) (2003) 792-793.

[3] F. Alves de Lima Ribeiro, M.M.C. Ferreira, J. Mol. Struct.: THEOCHEM 663 (1-3) (2003) 109-126.

[4] J.F. Brennecke, E.J. Maginn, Aiche J. 47 (11) (2001) 2384-2389.

[5] B.C. Lee, S.L. Outcalt, J. Chem. Eng. Data 51 (3) (2006) 892-897.

[6] J.M. Crosthwaite, S. Aki, E.J. Maginn, J.F. Brennecke, Fluid Phase Equilibr. 228 (2005) 303-309.

[7] A. Shariati, C.J. Peters, J. Supercrit. Fluids 34 (2) (2005) 171-176.

[8] J.S. Wilkes, Green Chem. 4 (2) (2002) 73-80.

[9] U. Krugle, M. Eckstein, N. Kaftzik, Biocatalytic reactions in ionic liquids, in: P. Wasserscheid, T. Welton (Eds.), Ionic Liquids in Synthesis, Wiley, Weinheim, 2003.

[10] S. Aki, B.R. Mellein, E.M. Saurer, J.F. Brennecke, J. Phys. Chem. B 108 (52) (2004) 20355-20365.

[11] S.N.V.K. Aki, A.M. Scurto, J.F. Brennecke, Ind. Eng. Chem. Res. 45 (2006) 55745585.

[12] L.A. Blanchard, Z.Y. Gu, J.F. Brennecke, J. Phys. Chem. B 105 (12) (2001) 24372444.

[13] C. Cadena, J.L. Anthony, J.K. Shah, T.I. Morrow, J.F. Brennecke, E.J. Maginn, J. Am. Chem. Soc. 126 (16) (2004) 5300-5308

[14] J. Jacquemin, M.F.C. Gomes, P. Husson, V. Majer, J. Chem. Thermodyn. 38 (4) (2006) 490-502.

[15] S. Zhang, Y. Chen, R.X.F. Ren, Y. Zhang, J. Zhang, X. Zhang, J. Chem. Eng. Data 50 (1) (2005) 230-233.

[16] Z.F. Zhang, W.Z. Wu, B. Wang, J.W. Chen, D. Shen, B.X. Han, J. Supercrit. Fluids 40 (1) (2007) 1-6.

[17] R.A. Khatri, S.S.C. Chuang, Y. Soong, M. Gray, Ind. Eng. Chem. Res. 44 (2005) 3702-3708.

[18] S. Ma'mun, H.F. Svendsen, K.A. Hoff, O. Juliussen, Energ. Convers. Manage. 48 (2006) 251-258.

[19] G. Yu, S. Zhang, X. Yao, J. Zhang, K. Dong, W. Dai, R. Mori, Ind. Eng. Chem. Res. 45 (2006) 2875-2880.

[20] E.D. Bates, R.D. Mayton, I. Ntai, J.H. Davis, J. Am. Chem. Soc. 124 (6) (2002) 926-927.

[21] L.A. Blanchard, J.F. Brennecke, Indus. Eng. Chem. Res. 40 (11) (2001) 2550.

[22] L.A. Blanchard, D. Hancu, E.J. Beckman, J.F. Brennecke, Nature 399 (6731) (1999) 28-29.

[23] E.M. Saurer, S. Aki, J.F. Brennecke, Green Chem. 8 (2) (2006) 141-143.

[24] A.M. Scurto, S. Aki, J.F. Brennecke, J. Am. Chem. Soc. 124 (35) (2002) 1027610277.

[25] M.C. Kroon, J. van Spronsen, C.J. Peters, R.A. Sheldon, G.J. Witkamp, Green Chem. 8 (3) (2006) 246-249. 
[26] J.K. Shah, E.J. Maginn, J. Phys. Chem. B 109 (20) (2005) 10395-10405.

[27] A.M. Scurto, S. Aki, J.F. Brennecke, Chem. Commun. (5) (2003) 572-573.

[28] Z. Zhang, W. Wu, H. Gao, B. Han, B. Wang, Y. Huang, Phys. Chem. Chem. Phys. 6 (2004) 5051-5055.

[29] Z. Zhang, W. Wu, Z. Liu, B. Han, H. Gao, T. Jiang, Phys. Chem. Chem. Phys. 6 (2004) 2352-2357.

[30] L. Ferguson, P. Scovazzo, Indus. Eng. Chem. Res. 46 (4) (2007) 1369-1374.

[31] T.F. Wang, C.J. Peng, H.L. Liu, Y. Hu, Fluid Phase Equilibr. 250 (1-2) (2006) 150157.

[32] J.L. Anthony, J.L. Anderson, E.J. Maginn, J.F. Brennecke, J. Phys. Chem. B 109 (13) (2005) 6366-6374.

[33] J.W. Hutchings, K.L. Fuller, M.P. Heitz, M.M. Hoffmann, Green Chem. 7 (6) (2005) 475-478.
34] D.B. Fu, X.W. Sun, J.J. Pu, S.Q. Zhao, J. Chem. Eng. Data 51 (2) (2006) 371-375

[35] D. Bessieres, H. Saint-Guirons, J.L. Daridon, J. Chem. Eng. Data 46 (5) (2001) 1136-1139.

[36] A.M.A. Dias, H. Carrier, J.-L. Daridon, J.C. Pàmies, L.F. Vega, J.A.P. Coutinho, I.M Marrucho, Ind. Eng. Chem. Res. 45 (2006) 2341-2350.

[37] S.P.M. Ventura, J. Pauly, J.L. Daridon, I.M. Marrucho, A.M.A. Dias, J.A.P. Coutinho, J. Chem. Eng. Data 52 (2007) 1100-1102.

[38] A. Shariati, K. Gutkowski, C.J. Peters, AIChE J. 51 (5) (2005) 1532-1540.

[39] A. Shariati, C.J. Peters, J. Supercrit. Fluids 29 (1-2) (2004) 43-48.

[40] A.Y. Sedykh, G. Klopman, J. Chem. Inf. Model 46 (4) (2006) 1598-1603.

JCT 07-311 